\title{
Simulation and test on separating cleaning process of flax threshing material based on gas-solid coupling theory
}

\author{
Fei Dai ${ }^{1}$, Xuefeng Song ${ }^{1}$, Wenjuan Guo $^{2}$, Wuyun Zhao ${ }^{1 *}$, Fengwei Zhang ${ }^{1}$, Shilin Zhang ${ }^{1}$ \\ (1. College of Mechanical and Electrical Engineering, Gansu Agricultural University, Lanzhou 730070, China; \\ 2. School of Cyber Security, Gansu Institute of Political Science and Law, Lanzhou 730070, China)
}

\begin{abstract}
In order to further clarify and improve the working performance of separating cleaning device of flax threshing material, and study the motion law and characteristics of components of flax threshing material, in this paper, numerical simulation was carried out on the separating cleaning process of flax threshing material based on CFD-DEM method. Simulation results showed that the components of flax threshing material were separated and cleaned under the influence of airflow field, meanwhile, variation curves of quantity and mean velocity of flax seeds in the separating cleaning system were obtained. By referring to streamline distribution of gas-solid coupling, the quantity variation law of components of flax threshing material with time was explored and their motion curves and variation tendency of average velocity were studied. Verification test results showed that the cleaning rate of separating cleaning device for flax threshing material was $92.66 \%$ with $1.58 \%$ of total separation loss. Compared with simulation results, the test results were $1.34 \%$ and $0.93 \%$ lower, showing that it is feasible to apply the gas-solid coupling theory and method to simulate the separating and cleaning operation of flax threshing material.
\end{abstract}

Keywords: flax threshing material, separating cleaning device, hydromechanics calculation, discrete element, numerical simulation, test

DOI: $10.25165 /$ j.ijabe.20201301.5196

Citation: Dai F, Song X F, Guo W J, Zhao W Y, Zhang F W, Zhang S L. Simulation and test on separating cleaning process of flax threshing material based on gas-solid coupling theory. Int J Agric \& Biol Eng, 2020; 13(1): 73-81.

\section{Introduction}

Flax, also called oil seed flax, is extensively distributed as an oil crop in 40 countries in five continents of the world, among which Asia and Europe have the largest planting area, followed by America. The countries with the highest flax production are India, the Soviet Union, Canada, the United States, and China. Flax is one of the important oil crops and cash crops in Northwest and North China ${ }^{[1]}$. At present, oil and fiber flax varieties are mainly grown in developed countries in Europe America, for the advantages of lodging-resistance and consistent maturity, and adaptability to mechanized combine harvesting with low content impurity rate, and can be directly sent for cleaning to obtain clean flax seeds; however, since the intelligent cleaning equipment in foreign countries has high precision as well as high price, it is not suitable for large-scale flax production in China ${ }^{[2]}$. Currently, flax is generally harvested in stages, and mechanized combine harvesting technology of flax and its equipment are still in testing

Received date: 2019-06-10 Accepted date: 2020-01-03

Biographies: Fei Dai, PhD candidate, Associate Professor, research interests: design of agricultural mechanization equipment, Email: daifei@gsau.edu.cn; Xuefeng Song, MS candidate, research interests: agricultural mechanization engineering, Email: 549349477@qq.com; Wenjuan Guo, MS candidate, research interests: computer simulation, Email: 565105996@qq.com; Fengwei Zhang, $\mathrm{PhD}$, Professor, research interests: agricultural mechanization engineering, Email: zhangfw@gsau.edu.cn; Shilin Zhang, Master candidate, research interests: agricultural mechanization engineering, Email: 619647034@ qq.com.

*Corresponding author: Wuyun Zhao, $\mathrm{PhD}$, Professor, research interests: farm machine and mechanical reliability. College of Mechanical and Electrical Engineering, Gansu Agricultural University, Lanzhou 730070, China. Tel: +86-451-7632472, Email: zhaowy@gsau.edu.cn. design and development. In order to satisfy the requirement of intensive processing, flax threshing material obtained under two working modes should be further separated and cleaned. Therefore, by considering the integration of orderly vibration feeding and efficient winnowing, and adopting the principle of separating cleaning by air flow, a separating cleaning device for flax threshing material was developed in this study.

There are generally two methods of grain separating cleaning: air-and-screen cleaning and airflow cleaning ${ }^{[3,4]}$. The former is more applied on rapeseed combine harvesters, which clean rapeseeds through a combination of fan and different types of vibrating sieves. However, for large size of sieves and complicated air duct, they are not suitable to work as key components of small-scale separating cleaning machine for flax threshing material. Cyclone separating cleaning system mainly adopts the principle of airflow cleaning, which is generally applied in agricultural machinery operation systems, such as small-scale rice-wheat combine harvester, rapeseed combine harvester, cyclone separating cleaning testbed, with advantages of good cleaning effects and compact structure, therefore, this principle can be applied in the separating cleaning operation of flax threshing material ${ }^{[5]}$. In view of the little difference of components of flax threshing material that are easily mixed together and can cause separation loss, the separating cleaning device for flax threshing material based on two-stage harvesting need to be further studied. Therefore, in order to improve the working performance of the device, based on gas-solid coupling theory, in this study, the CFD-DEM method was adopted for numerical simulation on the separating cleaning process of flax threshing material in the device, and the motion law and characteristics of the components of flax threshing material were studied to find out the quantity and velocity variation of threshing material in different regions. 


\section{Structure of separating cleaning device and working principle}

\subsection{Structure}

The separating cleaning device for flax threshing material is mainly composed of a vibrating feeding system, airflow cleaning system, vibrating frequency control box, residue discharge system, and material receiving device, dust collecting drum, body frame and road wheels. The structure of the separating cleaning device is shown in Figure 1.

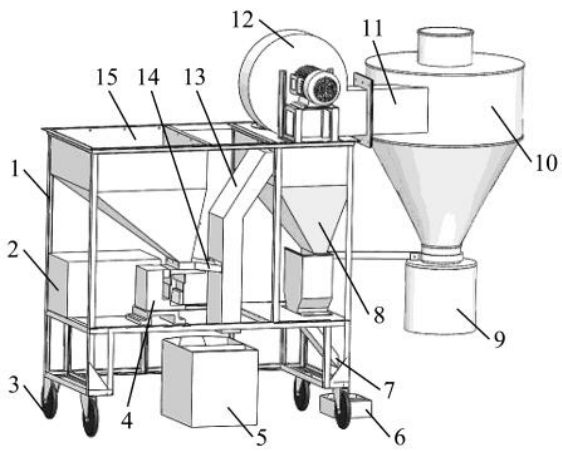

1. Body frame 2. Vibrating frequency control box 3. Road wheel 4. Electromagnetic vibration exciter 5. Flax seed receiver 6. Residue receiver 7. Residue outlet 8. Settlement hopper 9. Dust collecting drum 10. Cyclone separation dust remover 11. Dust collection pipe 12. Residue absorption fan 13. Seed separation device 14. Feed tray 15. Feeding hopper

Figure 1 Structure of the separating cleaning device for flax threshing material

Among them, the feeding system of the separating cleaning device is mainly composed of a feeding hopper, a feed tray, and a rear electromagnetic vibration exciter, and its vibration amplitude can be adjusted by the vibrating frequency control box ${ }^{[6]}$; the airflow cleaning system is mainly composed of a seed separation device, a seed receiver, a residue absorption fan, air pipe, dust collection pipe and a cyclone separation dust remover, and the rotating speed of the residue absorption fan is also adjusted by the vibrating frequency control box; the residue discharge system is mainly composed of a settlement hopper, an automatic residue discharge mechanism, a residue outlet and a residue receiver, which can realize discharge of residue of flax threshing material. Therefore, this device can separate and clean the components of flax threshing material and discharge the residue in different working regions. The main technical parameters of the operation machine are shown in Table 1.

Table 1 Main technical parameters of operation machine

\begin{tabular}{lc}
\hline \multicolumn{1}{c}{ Parameters } & Value \\
\hline Machine size $($ length $\times$ width $\times$ height $) / \mathrm{m} \times \mathrm{m} \times \mathrm{m}$ & $1.81 \times 0.83 \times 1.72$ \\
Total weight $/ \mathrm{kg}$ & 180 \\
Prototype power $/ \mathrm{kW}$ & 0.75 \\
Quality of automatic discharging discarded $/ \mathrm{kg}$ & $0.26-0.31$ \\
Electromagnetic exciter amplitude $/ \mathrm{mm}$ & $0-30$ \\
Conversion frequency of the suction $\mathrm{fan} / \mathrm{Hz}$ & $0-60$ \\
Rotate speed of the suction fan $/ \mathrm{r} \cdot \mathrm{min}^{-1}$ & $0-1800$ \\
Productivity $/ \mathrm{kg} \cdot \mathrm{h}^{-1}$ & 50 \\
\hline
\end{tabular}

\subsection{Working process analysis}

In the working process, the separating cleaning device for flax threshing material first adjusts vibration frequency of the electromagnetic vibration exciter and rotating speed of the residue absorption fan through the vibrating frequency control box. After harvesting by the combine harvester, the flax threshing material is fed through the feeding hopper, and under the influence of the inclination angle of the feeding hopper and the influence of intermittent vibration of the electromagnetic vibration exciter, flax threshing material is uniformly transmitted into the seed separation device. Currently, under the influence of the residue absorption fan, the material becomes suspended instantly, then the full flax seeds fall into the seed receiver under gravity. Meanwhile, the capsules, short stems, wizened or broken seeds of flax material enter the settlement hopper with the absorption airflow. With the increase of sectional area of the air duct of the hopper and slowdown of air velocity, the residue accumulates in the automatic residue discharge device along the inclined wall of the hopper. When the mixture of residue accumulates to a certain quantity, the automatic residue discharge device opens instantly and the residue falls into the residue receiver. Influenced by the residue absorption fan, dusts and light residue in the threshing material directly enter the cyclone separation dust remover, to ensure they enter into the dust collecting drum.

\section{Simulation-based mathematical model}

\subsection{Solid phase governing equation}

In the discrete element theory, the rectilinear motion and rotary motion of particles abide by Newton's second law ${ }^{[7]}$. In simulation calculation of separating cleaning of flax threshing material, first, the contact situation between particles in the computational domain is determined, then the acting forces, counterforces and displacement are determined based on Newton's third law, and the new unbalanced force between adjacent particles produced by relative displacement is calculated based on Newton's second law. The entire particle population is traversed by iterative calculation until the forces on particles become balanced ${ }^{[8]}$ The specific governing process can be described by Equations (1) and (2):

$$
\begin{gathered}
m_{i} \frac{d \vec{v}_{i}}{d t}=\sum f_{i} \\
I_{i} \frac{d \vec{\omega}_{i}}{d t}=\sum M_{i}
\end{gathered}
$$

where, $m_{i}$ is particle weight, $\mathrm{kg} ; t$ is acting time, $\mathrm{s} ; \vec{v}_{i}$ is particle velocity, $\mathrm{m} / \mathrm{s} ; f_{i}$ is the force on the particles, $\mathrm{N} ; I_{i}$ is rotary inertia of particles, $\mathrm{kg} \cdot \mathrm{m}^{2} ; \quad \vec{\omega}_{i}$ is angular velocity of particles, $\mathrm{rad} / \mathrm{s} ; M_{i}$ is the torque on particles, $\mathrm{N} / \mathrm{m}$.

\subsection{Gas phase governing equation}

The air motion in the flow field abides by the mass conservation equation, momentum conservation equation and energy conservation equation. The turbulence model in simulation is the $k-\varepsilon$ model, which has high robustness and can precisely capture the data variation of each point in a flow field ${ }^{[9-11]}$ The equations of kinetic energy $k$ and dissipation rate $\varepsilon$ in the standard $k-\varepsilon$ model are

$$
\begin{gathered}
\rho \frac{\mathrm{d} k}{\mathrm{~d} t}=\frac{\partial}{\partial x_{i}}\left[\left(\mu+\frac{\mu_{t}}{\sigma_{k}}\right) \frac{\partial k}{\partial x_{i}}\right]+G_{k}+G_{b}-\rho \varepsilon-Y_{M} \\
\rho \frac{\mathrm{d} \varepsilon}{\mathrm{d} t}=\frac{\partial}{\partial x_{i}}\left[\left(\mu+\frac{\mu_{t}}{\sigma_{\varepsilon}}\right) \frac{\partial \varepsilon}{\partial x_{i}}\right]+C_{1 \varepsilon} \frac{\varepsilon}{k}\left(G_{k}+G_{3 \varepsilon} G_{b}\right)-C_{2 \varepsilon} \rho \frac{\varepsilon^{2}}{k}
\end{gathered}
$$

where, $\rho$ is the fluid density, $\mathrm{kg} / \mathrm{m}^{3} ; \mu$ is the dynamic viscosity, $\mathrm{Pa} \cdot \mathrm{s}$; $x_{i}$ is the $x$ coordinate variable, $\mathrm{mm} ; G_{k}$ is the turbulence kinetic energy term caused by the average velocity gradient; $G_{b}$ is the turbulence kinetic energy term produced by buoyancy; $Y_{M}$ is the influence term of compressible turbulent pulsation expansion on total dissipation. The model constants are $C_{1 \varepsilon}=1.44, C_{2 \varepsilon}=1.92$, 
$C_{3 \varepsilon}=0.09$, with Turbulent Prandtl numbers of turbulence kinetic energy $k$ and dissipation rate of $\sigma_{k}=1.0, \sigma_{\varepsilon}=1.3$. Turbulence viscosity coefficient $\mu_{t}=\rho C_{\mu} \frac{k^{2}}{\varepsilon}$.

\section{Model establishment and parameter setting}

\subsection{Model establishment and computing mesh division}

The 3D structural diagram of the separating cleaning device for flax threshing material was drawn in Solidworks (Figure 2), then it was simplified by deleting irrelevant components in the simulation process. Then the diagram was saved as ". $\mathrm{x}_{-} \mathrm{t}$ " in universal data format and imported into ANSYS workbench. Then the fluid domain of the model was extracted by Geometry in ANSYS workbench, and at last, the highly adaptable unstructured tetrahedral mesh was adopted for mesh division in the meshing module. 139761 unstructured tetrahedral meshes were generated in the whole model, and among them, the fan had 5798 meshes $^{[12,13]}$.

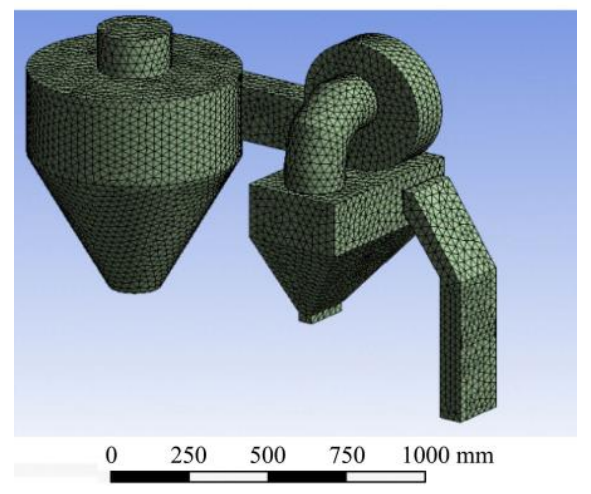

Figure 2 Mesh model of the separating cleaning device

Then the mesh model was imported in the FLUENT, after checking, no meshes of negative volume were produced, then MRF (Moving Reference Frame) was adopted for simulation.

\subsection{Material model and parameter setting}

According to the components of flax threshing material (Figure 3a), the three kinds of material entering the separating cleaning device during the numerical simulation process were seeds, glumes and dusts, as is shown in Figure $3 \mathrm{~b}, 3 \mathrm{c}, 3 \mathrm{~d}$ and $3 \mathrm{e}$ respectively.

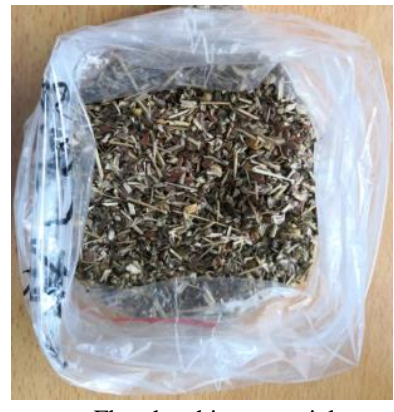

a. Flax threshing material

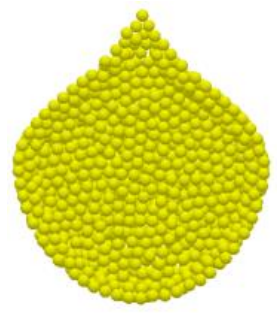

c. Glumes

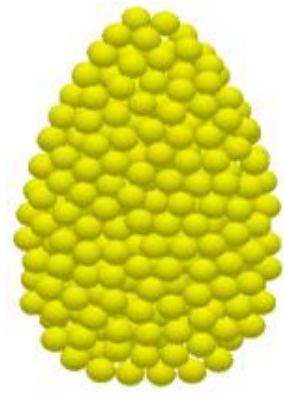

b. Seeds

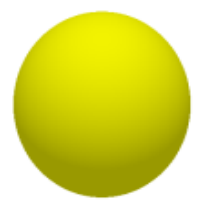

e. Dusts
Figure 3 Different components of flax threshing material and their discrete element models
The parameters of flax threshing material in EDEM are shown in Table 2. The recovery coefficients of all material were set as follows: particle-particle recovery coefficient was 0.2 , particle-stalk recovery coefficient was 0.2 ; recovery coefficient between particles and the enclosure wall was 0.5 ; the static friction factors of all material were set as follows: particle-particle static friction factor was 1 ; particle-stalk static friction factor was 0.8 , that between particles and the enclosure wall was 0.58 ; the dynamic friction factor among all material components was set as $0.01^{[14,15]}$.

Table 2 Flax threshing material parameters in EDEM

\begin{tabular}{cccc}
\hline Material & Poisson's ratio & Shear modulus/MPa & Density $/ \mathrm{kg} \cdot \mathrm{m}^{-3}$ \\
\hline Seeds & 0.25 & 10 & 750 \\
Glumes & 0.25 & 12 & 100 \\
Stems & 0.25 & 100 & 150 \\
Dusts & 0.25 & 100 & 50 \\
\hline
\end{tabular}

The feeding amount of the separating cleaning device for flax threshing material was set as $0.03 \mathrm{~kg} / \mathrm{s}$, according to the ratio of grain to straw and dust impurity of the flax threshing material, it was calculated that material produced 575 seeds, 1250 glumes, 1250 stems and 150 dust particles per second. Based on the results of previous researches, the rotating speed of the impurity absorption fan of the separating cleaning device was $1750 \mathrm{r} / \mathrm{min}$, time step in simulation was $1 \times 10^{-6} \mathrm{~s}$ and simulation lasted for $3 \mathrm{~s}$.

\subsection{Coupling parameter setting of the model}

Dynamic mesh model was adopted to simulate the rotation of the impurity absorption fan. By loading ".prof" file in boundary condition, the rotating speed of the fan can be controlled (rotating speed was the same with that set by EDEM). Time step in simulation was $1 \times 10^{-4} \mathrm{~s}$.

Gas phase simulation was carried out in FLUENT by taking air as fluid medium with density of $1.2 \mathrm{~kg} / \mathrm{m}^{3}$ and viscosity of $1.8 \times 10^{-5} \mathrm{~Pa} \cdot \mathrm{s}$. Standard $k-\varepsilon$ was taken as the turbulence model for transient calculation. The wall surface of the pipeline was a non-slip wall. The pressure-based SILPLE algorithm was applied to solve the velocity field and the pressure field. Second order upwind scheme was adopted for the momentum term. First-order upwind scheme was adopted for the turbulent flow kinetic energy and turbulent dissipation rate with residual accuracy of $10^{-3} \mathrm{~s}$. In coupling calculation, since the solid phase volume fraction was less than $10 \%$, which belongs to dilute phase pneumatic conveying system, so the Euler-Lagrangian coupling model was selected. The Ergun and Wen \& Yu model that can well adapt to the void ratio was adopted as drag force model, meanwhile, Magnus lift and Sevman shear were recorded ${ }^{[16,17]}$.

\section{Simulation process and result analysis}

\subsection{Threshing material motion law in separating cleaning}

In the early relevant work performance test of prototype, when the electromagnetic exciter amplitude of the vibration feeding system was controlled at $14-18 \mathrm{~mm}$, and the conversion frequency of the suction fan of the air cleaning system was controlled at $50-60 \mathrm{~Hz}$ (the corresponding rotating speed is $1500-1800 \mathrm{r} / \mathrm{min}$ ), the operating machine had a strong adaptability to flax threshing material ${ }^{[18]}$. So according to the working principle of the separating cleaning device for flax threshing material, the motion process and law were simulated by setting the rotating speed of the residue absorption fan as $1250 \mathrm{r} / \mathrm{min}, 1500 \mathrm{r} / \mathrm{min}$ and $1750 \mathrm{r} / \mathrm{min}$ respectively, to produce components of flax threshing material (seeds, glumes and stems) and dusts at initial speed of $0 \mathrm{~m} / \mathrm{s}$. 


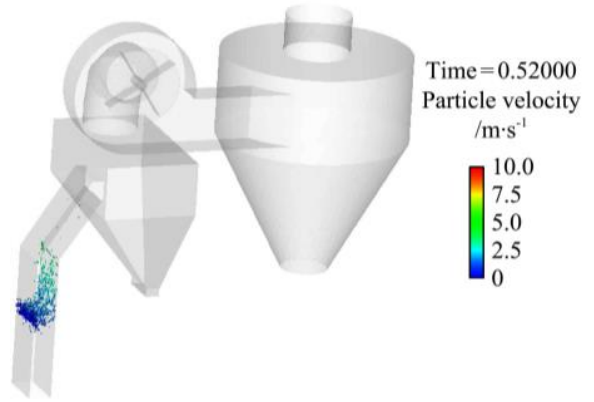

a. $0.52 \mathrm{~s}$

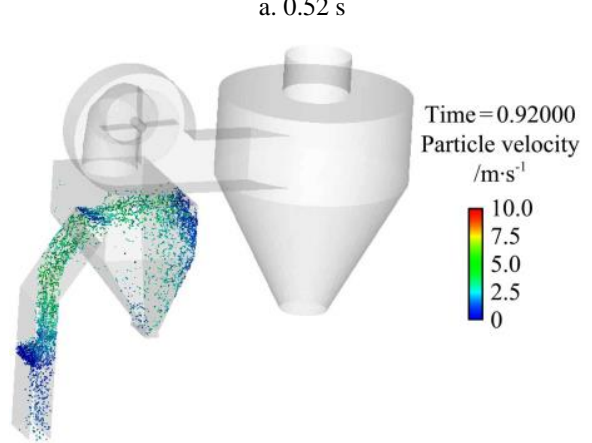

d. $0.92 \mathrm{~s}$

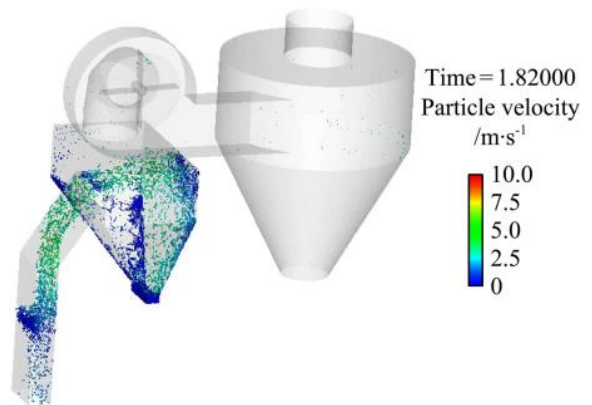

g. $1.82 \mathrm{~s}$

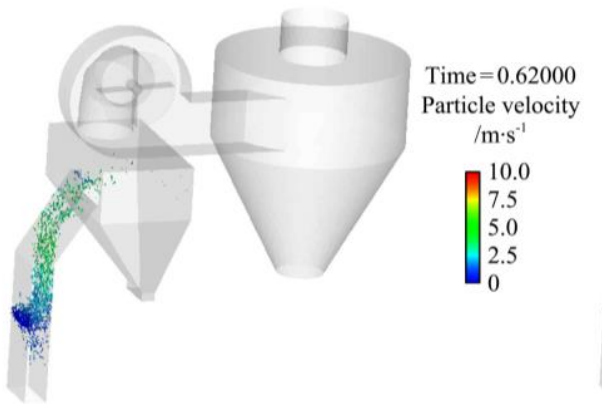

b. $0.62 \mathrm{~s}$
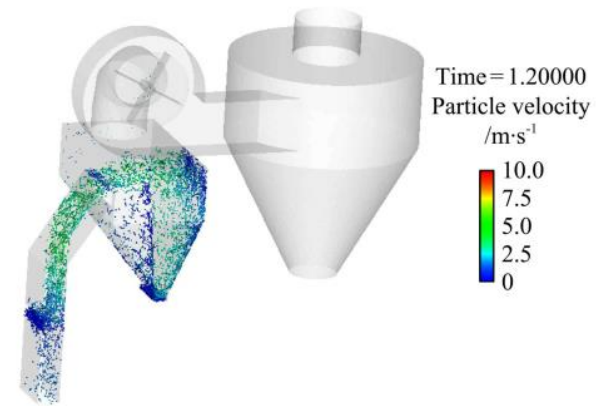

e. $1.20 \mathrm{~s}$

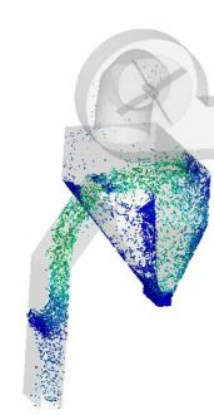

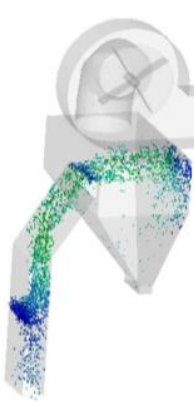

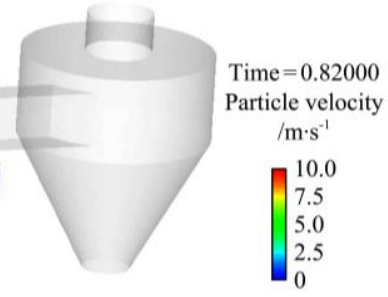

c. $0.82 \mathrm{~s}$
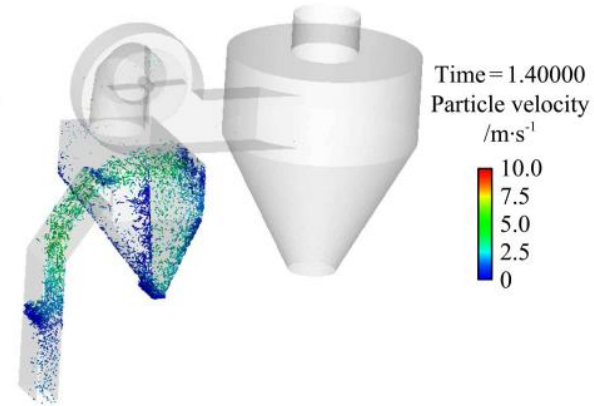

f. $1.40 \mathrm{~s}$
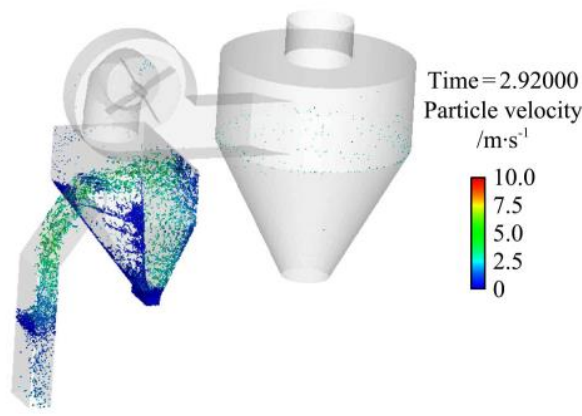

i. $2.92 \mathrm{~s}$

Figure 4 Motion process and law of threshing material in separating cleaning

The simulation time tends to be stable after $3 \mathrm{~s}$, so the Figure $4 \mathrm{a}-4 \mathrm{i}$ show the motion process and law of flax threshing material in the separating cleaning device when the rotating speed of the residue absorption fan was $1750 \mathrm{r} / \mathrm{min}$ during time period $t=0.52-2.92 \mathrm{~s}$. Since CFD-DEM coupling was started under the condition of convergent and stable flow field, when $t=0 \mathrm{~s}$, the EDEM numerical simulation was approximately the working status of the separating and threshing device for flax threshing material. When $t=0.52 \mathrm{~s}$, the threshing material plant started to produce flax seeds, glumes, stems and dusts with a feeding quantity of $0.03 \mathrm{~kg} / \mathrm{s}$ and an initial speed of $0 \mathrm{~m} / \mathrm{s}$, and became instantaneously suspended after entering the seed separation device, as is shown in Figure 6a. When $t=0.62 \mathrm{~s}$, flax threshing material was separated under the influence of negative pressure produced by the rotation of the residue absorption fan. The full flax seeds fell into the seed receiver under gravity, and at the same time, flax glumes, stems and dusts fell into the settlement hopper through the seed separation device. When $t=0.82-1.20 \mathrm{~s}$, disturbed by the rotary airflow field of the residue absorption fan, flax threshing material started flip-flop movement in the settlement hopper, and in this process, the threshing material was mainly influenced by gravity, pressure gradient force, drag force, spinning lift force and the impact from hopper wall, and some flax glumes, stems and just a few seeds were retained at the lower end of the settlement hopper. Stirred by the winnower of the residue absorption fan, the dust particles in the threshing material accelerated the air within the device and entered the cyclone separation dust remover through dust collection pipe (Figure 4f). When $t=1.82 \mathrm{~s}$ the dust particles in the threshing material became suspended in the cyclone separation dust remover, and started circular motion around the drum of the dust remover to realize dust separation. When $t=2.32-2.92 \mathrm{~s}$, the material quantity in the flax separating cleaning device kept stable. After threshing material entered the device, different components can be separated and cleaned under influence of high-speed air flow. Meanwhile, it was found in the simulation process that, for the light weight of flax seeds and glumes, a few seeds were brought into the settlement hopper under the high-speed rotation of the residue absorption fan, and glumes also enter the dust remover with material and dusts ${ }^{[19]}$. Therefore, other than the feeding quantity of threshing material and vibration amplitude, the influence of the rotating speed of the residue absorption fan on the separating cleaning effects of the device was very important. After simulation of separating cleaning, the results were calculated and analyzed, and the grain cleaning rate after numerical simulation was $91.32 \%$ with total separation loss of $2.51 \%$.

\subsection{Quantity variation of flax seeds in the entire region}

In the process of separating cleaning, flax threshing material is mainly composed of seeds, glumes, stems and dusts. The separating cleaning of flax seeds were the most important and the number of flax seeds were the key to seed cleaning rate. Under the rotating speed of residue absorption fan of $1750 \mathrm{r} / \mathrm{min}$, the 
quantity variation curve and tendency of flax seeds in the entire region is shown in Figure 5.

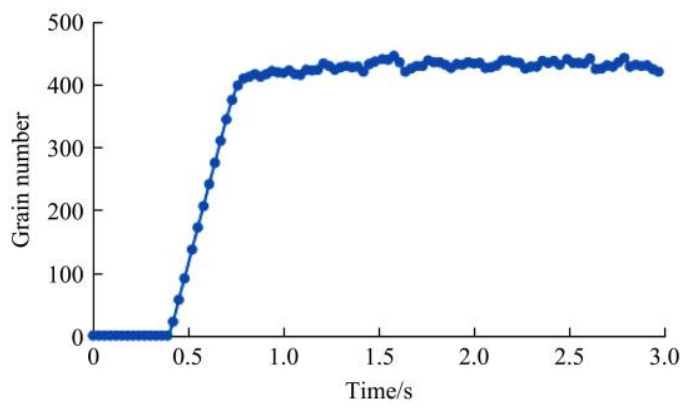

Figure 5 Variation curve of quantity of particles with time in the entire region

Figure 5 shows that, when $t=0.40 \mathrm{~s}$, flax threshing material entered the seed separation device under the influence of electromagnetic vibration exciter and material receiver, and flax seeds increased in a linear trend when $t=0.40-0.75 \mathrm{~s}$. It was found in the simulated motion process and law of the flax threshing material in separating cleaning that, flax seeds were mainly concentrated in the seed separation device and the settlement hopper. Therefore, after $t=1.00 \mathrm{~s}$, along with the continuous operation of residue absorption fan, the flow field within the separating cleaning device was basically stable, and the number of flax seeds in the above-mentioned regions were basically consistent, in this case, continuous particle flow of flax seeds at the lower end of the seed separation device fell into the material receiver under gravity.

\subsection{Velocity variation of flax seeds in the entire region}

The variation curve of the velocity of flaxseeds with time in the entire region is shown in Figure 6. When $t=0.40-0.80 \mathrm{~s}$, flax seeds enter into seed separation device with threshing material and became suspended under the influence of residue absorption fan. The velocity of flax seeds gradually increased with time of moving. At around $t=0.80 \mathrm{~s}$, the average velocity of flax seeds changed abruptly. This was because the full flax seeds suddenly dropped under gravity to the seed receiver after the status of instantaneous suspension. After $t=1.10 \mathrm{~s}$, the velocity of flax seeds became stable and kept at around $0.90 \mathrm{~m} / \mathrm{s}$.

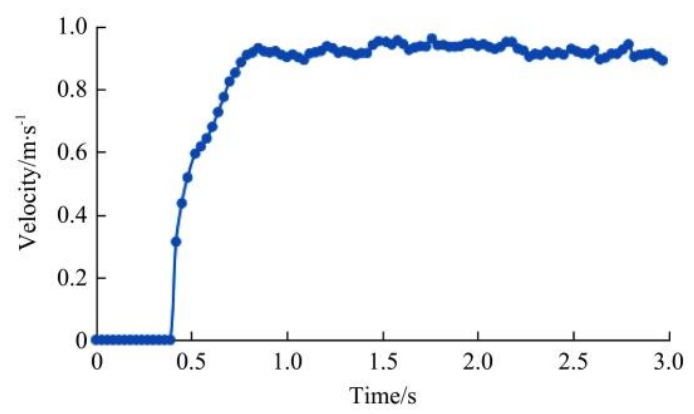

Figure 6 Velocity variation curve of flax seeds with time in the entire region

5.4 Variation of quantity and velocity of components of flax threshing material in different regions

Material retention in each region in the device after separating cleaning is one of the most important performance indicators that influence cleanliness of flax harvesting. During the test, it was found that the components of flax threshing material were found in the four regions as shown in Figure 7. Therefore, it is necessary to analyze the quantity and moving velocity of the components of material from region 1 and region 4 under influence of solid-gas flow, to find out the influencing factors for retention of components of the threshing material ${ }^{[20,21]}$.

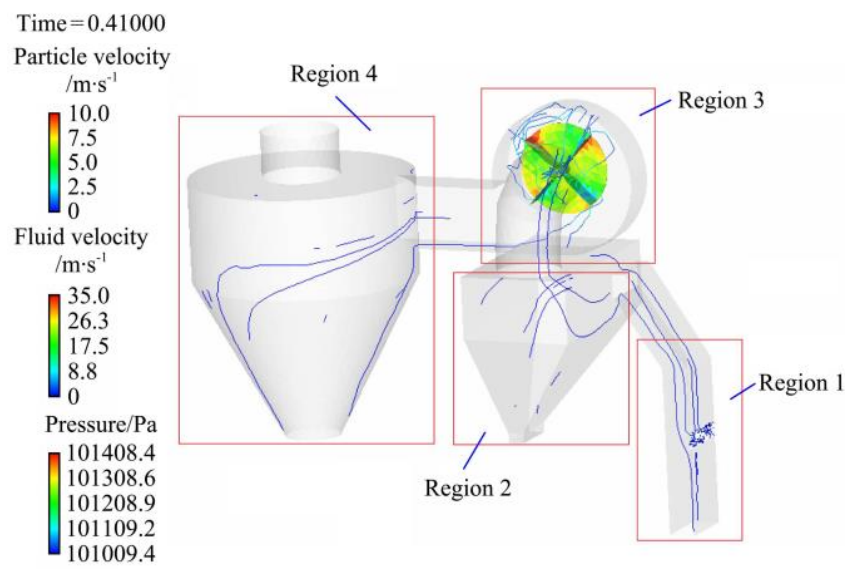

Figure 7 Different motion regions of flax threshing material in separating cleaning process

The study above shows that, the material kept at stable status after $t=0.80 \mathrm{~s}$. Therefore, under rotating speed of $1450 \mathrm{r} / \mathrm{min}$ of the residue absorption fan, the separating cleaning process of material in the device was observed and analyzed based on CFD-DEM coupling, and the variation of quantity and average velocity of flax threshing material in different regions is shown in Figure 8 and Figure 9.

The streamline trajectories in Figure 8a-e show that, flax seeds mainly stayed in region 1 and region 2 , and formed a continuous particle flow in the seed separation device. In the region 2 of the settlement hopper, the flow field distribution and streamlines were in disorder, mainly because the region was a key unit that connected the seed separation device and residue absorption fan as well as cyclone separation dust remover. The four different components of flax threshing material had motion and retention in mixture, which seriously disturbed the distribution of flow field of gas-solid coupling. The distribution streamlines in the residue absorption fan show that, the wind pressure in region 3 basically kept unchanged and intensity of pressure was the highest at the contacting point at the tip of the blades and decreased gradually long the rotating direction. In the region 4 in the cyclone separation dust remover, the main material was dusts, therefore, the flow field distribution was uniform in the drum and streamline trajectories were consistent. The dusts had centrifugal rotation along the drum wall of the cyclone separation dust remover and discharged through the lower outlet.

The variation curves of the quantity of components of flax threshing material with time in different regions are shown in Figure 9.

Figure 9a shows that, flax seeds were mainly in region 1 of the separating cleaning system. Only several seeds in region 3 were retained and no flax seeds entered in the region 4 , indicating that some of the seeds in region 3 might circulate along with the rotary flow field of the residue absorption fan. The variation tendency of the quantity of flax stems and glumes in each region was basically the same (Figures $9 b$ and 9c), and mainly accumulated in the hopper region 2 , since there were insignificant difference in mass of them; flax stems and glumes were discharged through the automatic residue discharge mechanism after accumulating to a certain amount, therefore, the number of flax stems and glumes increased linearly after $0.7 \mathrm{~s}$. Figure $9 \mathrm{~d}$ shows that the dusts did not stay in region 1 and region 2 after entering the separation device in the early stage, so the variation tendencies in the two 
regions were relatively consistent. Except for a very small number of flax stems and glumes, almost all the dusts entered the cyclone separation dust remover influenced by the residue absorption fan, and rotated along with the suspended airflow. More and more dust particles accumulated in the cyclone

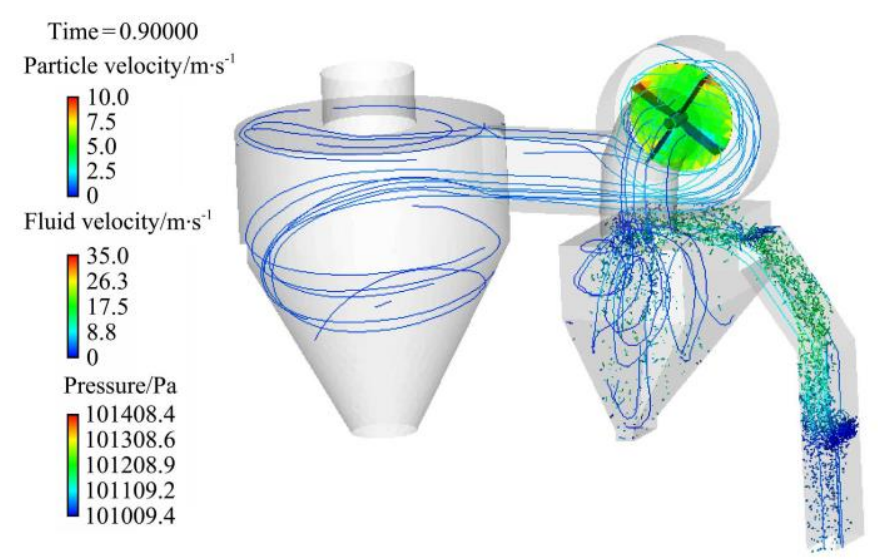

a. $0.90 \mathrm{~s}$

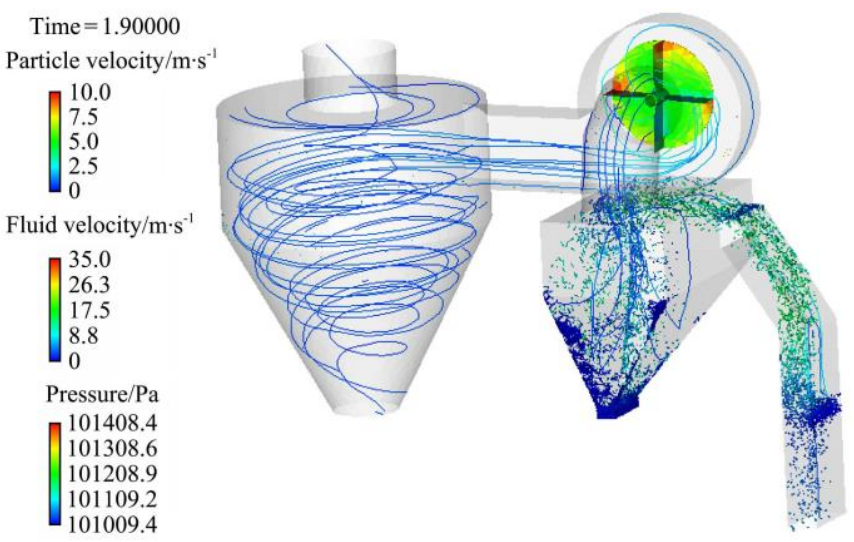

c. $1.90 \mathrm{~s}$ separation dust remover.

The variation curves of the average velocity of components of flax threshing material with time in different regions are shown in Figure 10.
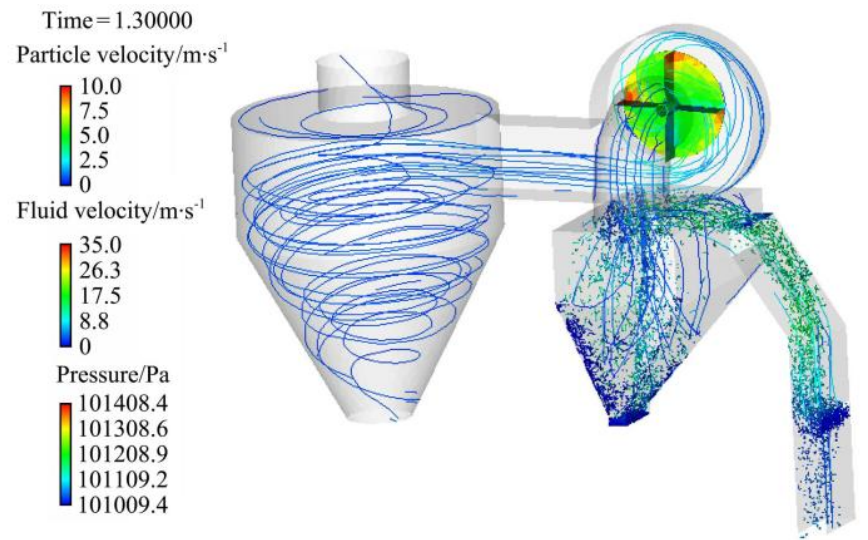

b. $1.30 \mathrm{~s}$
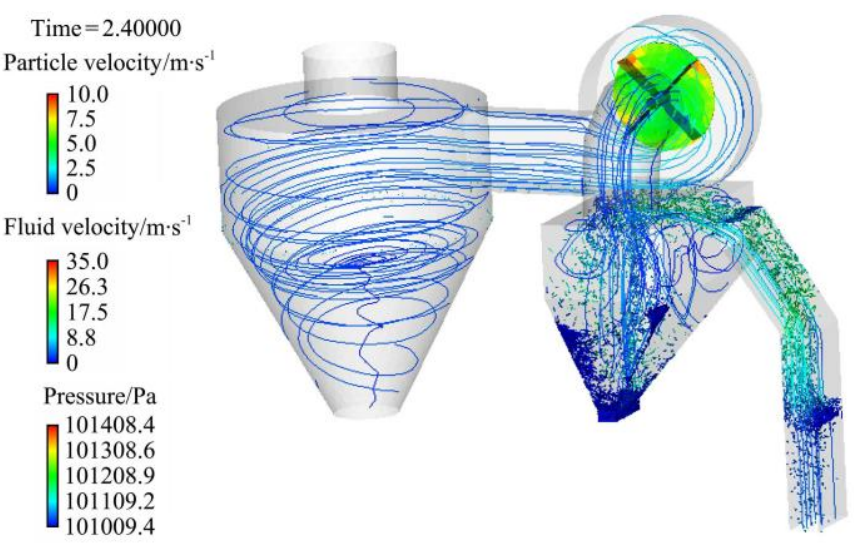

d. $2.40 \mathrm{~s}$

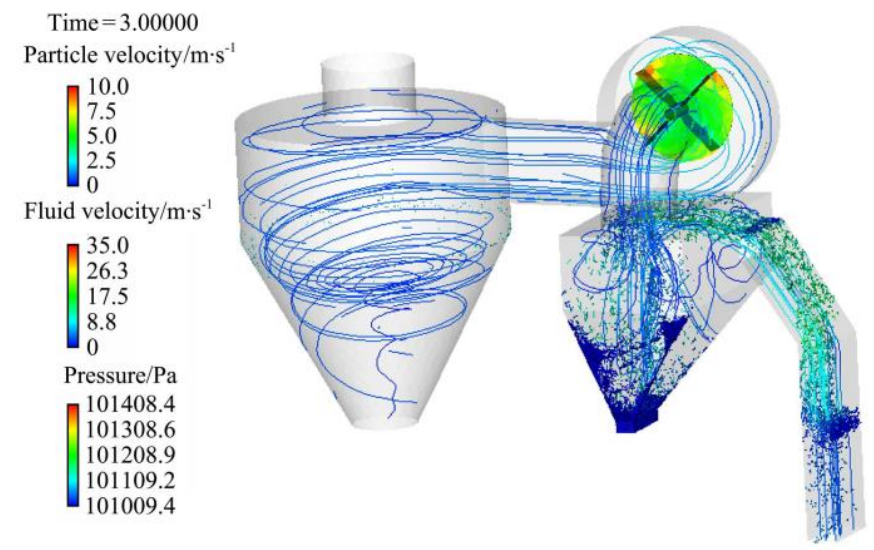

e. $3.00 \mathrm{~s}$

Figure 8 Motion analysis on components of flax threshing material in different regions

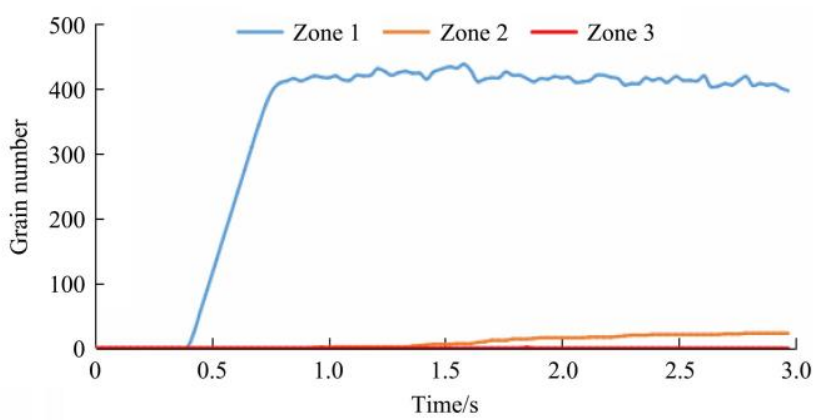

a. Quantity variation of flax seeds in different regions

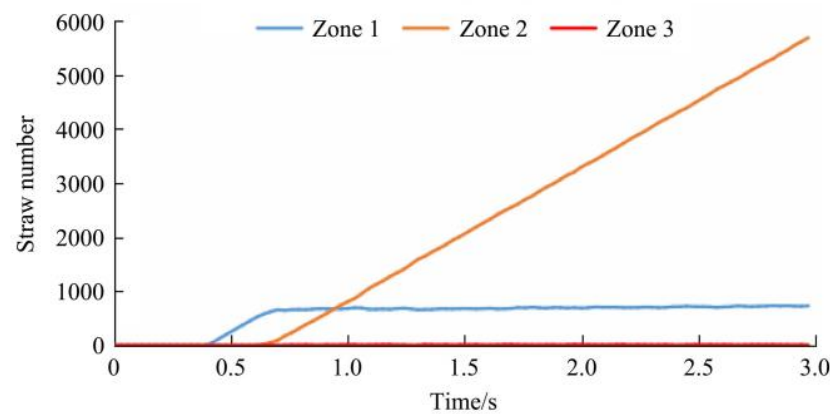

b. Quantity variation of stems in different regions 


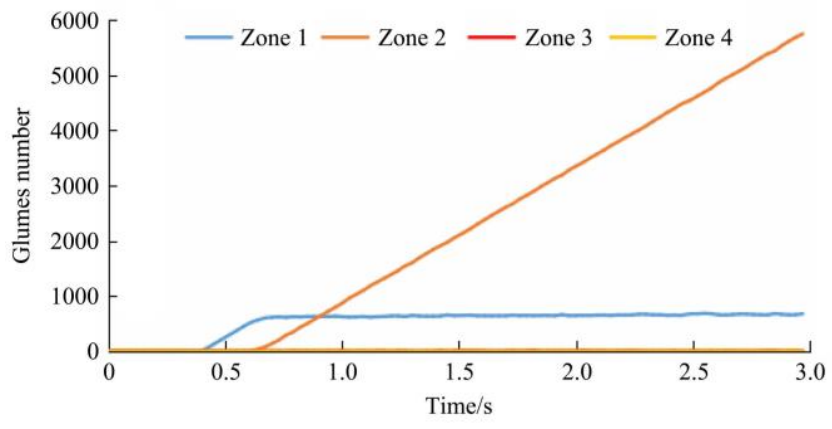

c. Quantity variation of flax glumes in different regions

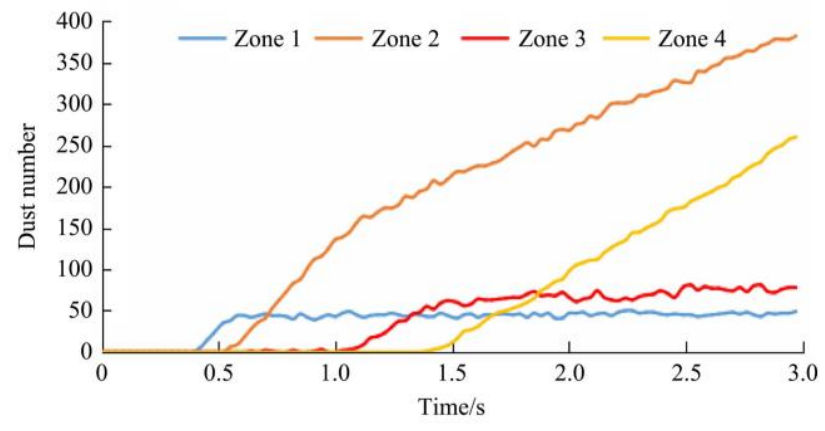

d. Quantity variation of dusts in different regions

Figure 9 Variation curves of quantity of components of flax threshing material with time in different regions

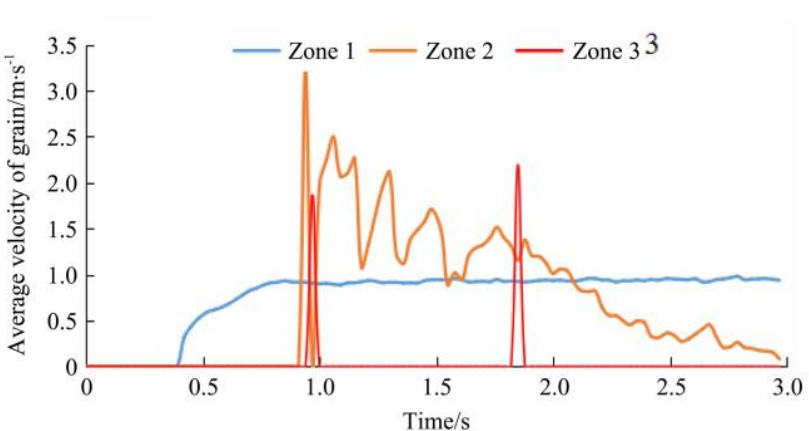

a. Mean velocity variation of flax seeds in different regions

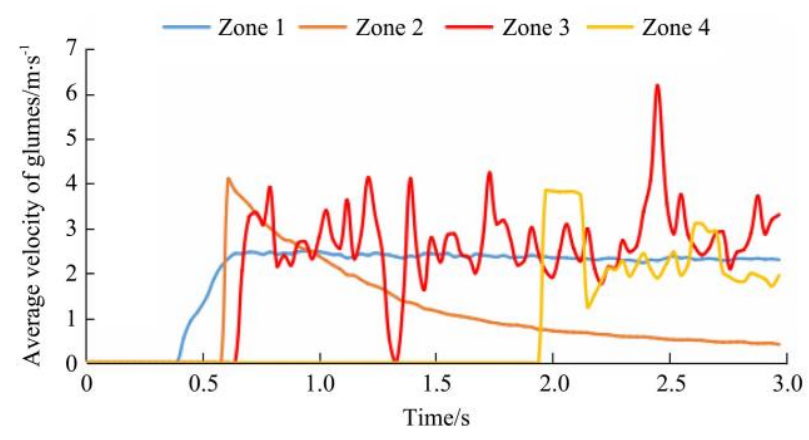

c. Mean velocity variation of flax glumes in different regions

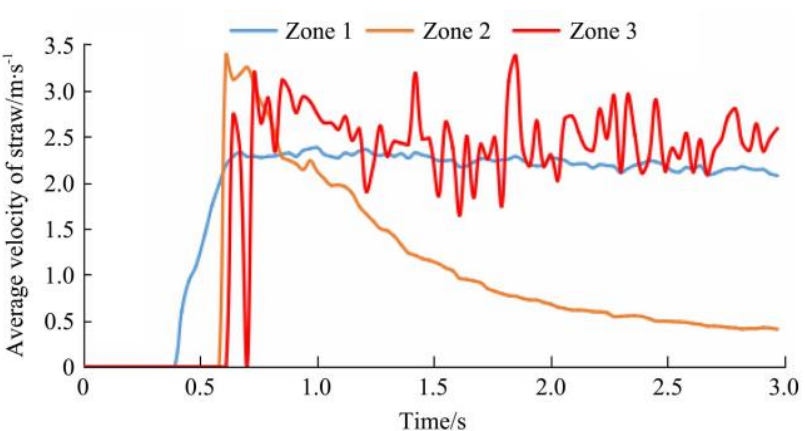

b. Mean velocity variation of flax stems in different regions

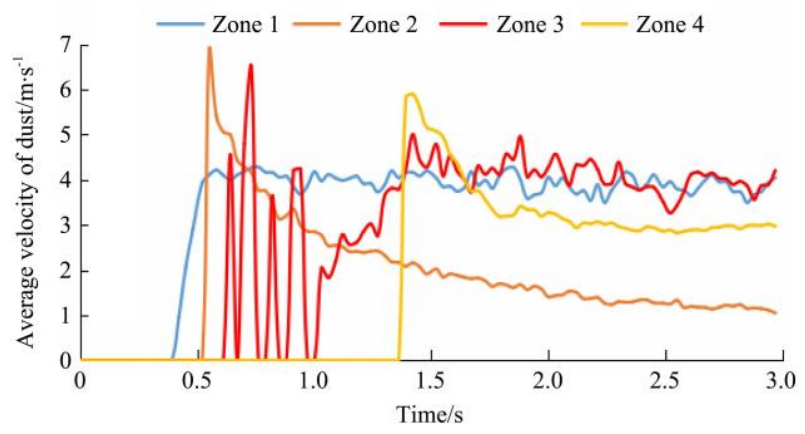

d. Mean velocity variation of dusts in different regions

Figure 10 Variation curves of the average velocity of components of flax threshing material with time in different regions

Figure 10a shows that when flax seeds fall in a continuous particle flow in the separation device, the speed of falling into the seed receiver was stable, which was about $1 \mathrm{~m} / \mathrm{s}$; some seeds had flip-flop movement in the 2 nd region of the settlement hopper and gradually fell into the automatic residue discharge mechanism at last, and the seed velocity reduced from $3.25 \mathrm{~m} / \mathrm{s}$ to $0 \mathrm{~m} / \mathrm{s}$. It can be observed from Figure 10b and 10c that, the variation tendency of average velocity of flax stems and glumes in region 1 was basically the same: the movement speed began to increase after $0.4 \mathrm{~s}$ and became stable when it reached $2.5 \mathrm{~m} / \mathrm{s}$. Most flax stems and glumes in the threshing material were separated and retained in the hopper region 2, however, for light weight, the stems and glumes accumulated at the bottom of the hopper still had flip-flop movement influenced by the swirling airflow field in region 2 . Therefore, the final motion velocity remains at $0.5 \mathrm{~m} / \mathrm{s}$. In the region 3 of the residue absorption fan, velocity curves show that the average velocity of the flax stems fluctuated between 1.5 and $3.0 \mathrm{~m} / \mathrm{s}$, and the average velocity of flax glumes was kept at 1.5 to $4.0 \mathrm{~m} / \mathrm{s}$. It shows that a small amount of flax stems and glumes were permanently retained in the enclosure of the residue absorption fan and fluctuated within a certain range of velocity with the rotation of fan blades. It is also found that there are several flax glumes entering into the cyclone separation dust remover along with the flax glumes after $1.9 \mathrm{~s}$. Figure 10d shows that, the dusts had obvious variation tendency in velocity with initial motion time of $1 \mathrm{~s}$ in region 3 . After $1.5 \mathrm{~s}$ when the flow field of the separating cleaning system became stable, the mixed dusts were sent into cyclone separation dust remover by the residue absorption fan at a stable velocity, and the suspended velocity of dusts in the cyclone separation dust remover kept changing around $3.0 \mathrm{~m} / \mathrm{s}$.

\section{Test verification}

In August 2018, the on-site operation demonstration and operation performance test of the separation and sorting device for flax threshing material were carried out in Tiaoshan Farm of Jingtai County, Gansu Province. The test material was selected from the threshing material (mainly flax seeds, capsules and short stems) of Longya No. 14 during flax harvesting. The average number of capsules per plant was 24.1 and the average number of capsules was 7.2 , and the average thousand seed mass was $8.1 \mathrm{~g}$, the yield per plant was $0.95 \mathrm{~g}$, and the moisture content of the threshing material was $11.6 \%$. Before the test, the test machine was in racing, and the vibration amplitude in feeding $(0-30 \mathrm{~mm})$ and the variable frequency of rotating speed of the residue absorption fan $(0-60 \mathrm{~Hz})$ were debugged. 
According to the expected design function of the test machine and based on the test method specified in the national standard GB/T 5262-2008 General Rules for Measuring Methods of Agricultural Machinery Test Conditions, the working performance test was carried out (Figure 11), and the power of the device was $0.75 \mathrm{~kW}$. After the device was in normal operation after racing, flax threshing material during harvesting period was added into the feeding hopper ${ }^{[22-24]}$. Seed cleaning rate, total separation loss, and clogging of automatic residue discharge mechanism were taken as testing indexes for working performance of the device; at the same time, the operation situation of the vibration feeding system, the seed separation device, automatic residue discharge mechanism and the airflow clearing system were studied.

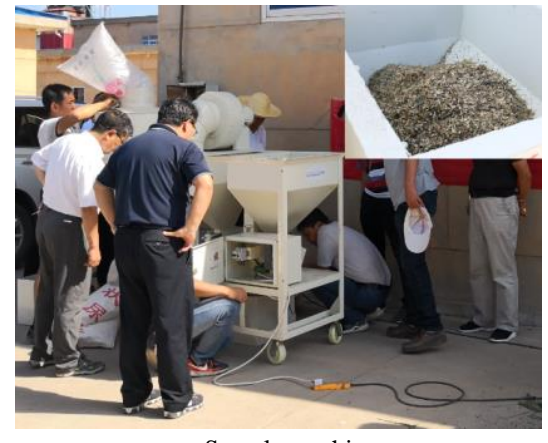

a. Sample machine

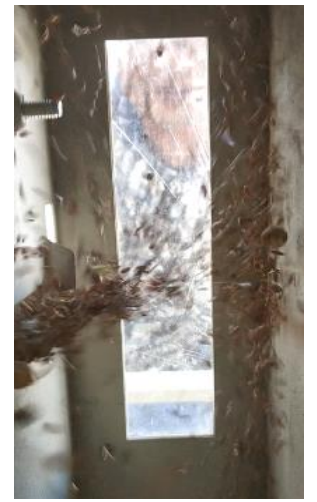

b. Movement track of flax threshing material in the seed separation device

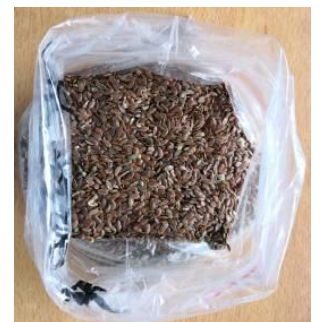

c. Separating cleaning of flax seeds

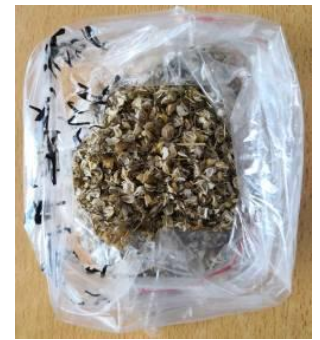

d. Separating cleaning of flax stems and glumes

Figure 11 Verification test on the separating cleaning device for flax threshing material

Test results showed that the grain cleaning rate of the separating cleaning machine for flax threshing material was $92.66 \%$ with total separation loss of $1.58 \%$, and it could realize separating cleaning of flax threshing material during harvesting period. Compared with simulated seed cleaning rate $(91.32 \%)$ and total separation loss $(2.51 \%)$, the test results were $1.34 \%$ and $0.93 \%$ higher, showing basic consistency between test results and simulation results, and the correctness of simulation results of the separating cleaning process for flax threshing material based on gas-solid coupling theory.

\section{Conclusions}

1) Through analysis on the working process of the flax separating cleaning device, the fluid governing equation in the device and gas-solid coupling were established; and non-sliding contact model and mathematical model of particles, and particle model of all components of flax threshing material were established based EDEM, and calculation domain of fluid were also established based on FLUENT.

2) Numerical simulation was made on the motion process of flax threshing material in the separating cleaning device, and variation curves of quantity and mean velocity of flax particles in the whole region were obtained. By referring to streamline distribution of gas-solid coupling, the quantity variation law of components of flax threshing material with time was explored and its motion curve and variation tendency of average speed were studied.

3) Verification test was carried out by taking seed cleaning rate and total separation loss as the indexes of working performance of flax separating cleaning device, the cleaning rate of separating cleaning device for flax threshing material was $92.66 \%$ with $1.58 \%$ of total separation loss and it was found that the test results and simulation results were basically consistent, and test results were $1.34 \%$ and $0.93 \%$ lower, showing that it is feasible to apply the gas-solid coupling theory and method to simulate the separating and cleaning operation of flax threshing material.

\section{Acknowledgements}

The authors acknowledge that this work was financially supported by China Agriculture Research System (CARS-14-1-28), Discipline construction fund project of Gansu Agricultural University (GAU-XKJS-2018-189).

\section{[References]}

[1] Wang L M, Zhang J P, Dang Z, Pei X W, Dang Z H. The analysis of the parental combining ability and heterosis on two-line hybrid flax. Scientia Agricultura Sinica, 2016; 49(6): 1047-1059. (in Chinese)

[2] Dujardin N, Fois M, Grimau M, Poilane C. Soft interface dynamics in flax-fabrics/epoxy composites. Composite Structures, 2018; 202: 389-396.

[3] Liao Q X, Chen L, Li H T, Han C R, Liu M F. Cleaning unit test-bed of extraction components for rape combine harvester. Transactions of the Chinese Society for Agricultural Machinery, 2013; 44(10): 80-85, 79. (in Chinese)

[4] Fu J, Chen Z, Tian L Q, Han L J, Ren L Q. Review of grain threshing theory and technology. Int J Agric \& Biol Eng, 2018; 11(3): 12-20.

[5] Jerzy M, Wojciech M, Grzegorz S, Jacek K, Andrzej K, Damian K, et al Research on new technology of fiber flax harvesting. Journal of Natural Fibers, 2018; 15(1): 53-61.

[6] Jin X, Zhao K X, Ji J T, Du X W, Ma H, Qiu Z M. Design and implementation of intelligent transplanting system based on photoelectric sensor and PLC. Future Generation Computer Systems, 2018; 88(1): 127-139.

[7] Kuang S B, Yu A B, Zou Z S. Computational study of flow regimes in vertical pneumatic conveying. Industrial \& Engineering Chemistry Research, 2009; 48(14): 6846-6858.

[8] Peng Z B, Doroodchi E, Moghtaderi B, Evans G M. A DEM-based 
analysis of the influence of aggregate structure on suspension shear yield stress. Advanced Powder Technology, 2012; 23(4): 437-444.

[9] Li H C, Li Y M, Gao F, Zhao Z, Xu Li Z. CFD-DEM simulation of material motion in air-and-screen cleaning device. Computers and Electronics in Agriculture, 2012; 88(6): 111-119.

[10] Zhao Z, Li Y M, Liang Z W, Gong Z Q. DEM simulation and physical testing of rice seed impact against a grain loss sensor. Biosystems Engineering, 2013; 116: 410-419.

[11] Liu H X, Guo L F, Fu L L, Tang S F. Study on multi-size seed-metering device for vertical plate soybean precision planter. Int J Agric \& Biol Eng, 2015; 8(1): 1-8.

[12] He Y, Bayly A E, Hassanpour A L. Coupling CFD-DEM with dynamic meshing: A new approach forfluid-structure interaction in particle-fluid flows. Powder Technology, 2018; 325: 620-631.

[13] Dai F, Song X F, Zhao W Y, Han Z S, Zhang F W, Zhang S L. Motion simulation and test on threshed grains in tapered threshing and transmission device for plot wheat breeding based on CFD-DEM. Int $\mathbf{J}$ Agric \& Biol Eng, 2019; 12(1): 66-73.

[14] Jiang E C, Sun Z F, Pan Z Y, Wang L J. Numerical simulation based on CFD-DEM and experiment of grain moving laws in inertia separation chamber. Transactions of the CSAM, 2014; 45(4): 117-122. (in Chinese)

[15] Liu L Y, Hao S Y, Zhang M, Liu D M, Jia F G, Quan L Z. Numerical simulation and experiment on paddy ventilation resistance based on CFD-DEM. Transactions of the CSAM, 2015; 46(8): 27-32. (in Chinese)

[16] Boac J M, Ambrose R P K, Casada M E, Maghirang R G, Maier D E. Applications of discrete element method in modeling of grain postharvest operations. Food Engineering Reviews, 2014; 6(4): 128-149.

[17] Oldal I, Safranyik F. Extension of silo discharge model based on discrete element method. Journal of Mechanical Science \& Technology, 2015; 29(9): 3789-3796.

[18] Dai F, Zhao W Y, Liu G C, Zhang S L, Shi R J, Wei B. Design and experiment of separating and cleaning machine for flax threshing material. Transactions of the CSAM, 2019; 50(8): 140-147. (in Chinese)

[19] Wang J W, Zhou W Q, Tian L Q, Li S W, Zhang Z. Virtual simulation analysis and verification of seed-filling mechanism for dipper hill-drop precision direct rice seeder. Int J Agric \& Biol Eng, 2017; 10(6): 77-85.

[20] Ma L C, Wei L B, Pei X Y, Zhu X S, Xu D R. CFD-DEM simulations of particle separation characteristic in centrifugal compounding force field. Powder Technology, 2019; 343: 11-18.

[21] Wang S Y, Li H L, Wang R C, Wang X, Tian R C, Sun Q J. Effect of the inlet angle on the performance of a cyclone separator using CFD-DEM. Advanced Powder Technology, 2019; 30(2): 227-239.

[22] Bart L, Bart M, Josse D B, Wouter S. LiDaR sensing to monitor straw output quality of a combine harvester. Computers and Electronics in Agriculture, 2012; 85(1): 40-44.

[23] Tang Z, Li Y M, Xu L Z, Francis K. Modeling and design of a combined transverse and axial flow threshing unit for rice harvesters. Spanish Journal of Agricultural Research, 2014; 12(4): 973-983.

[24] Jiří S, Tomáš S, Jan M. Analysis of linseed production with use of flax puller and combine harvester for its harvest. Acta Universitatis Agriculturae et Silviculturae Mendelianae Brunensis, 2017; 65(2): 511-517. 